To the Editors:

\title{
Acute upper gastrointestinal haemorrhage in Sri Lankan adults - single unit experience
}

In Sri Lanka, oesophageal varices are the commonest cause of acute upper gastrointestinal haemorrhage [1].

We studied 1240 consecutive referrals to our unit with upper gastrointestinal bleeding (haemetemesis and / or melaena) from April 2004 to April 2009. All patients underwent upper gastrointestinal endoscopy (GIF -140 or GIF -160 Olympus - Tokyo, Japan) under topical anaesthesia with xylocain ${ }^{\mathrm{TM}}$ pharyngeal spray, except 5 who needed sedation with intravenous midazolam (dormicum $^{\mathrm{TM}}$ ). The cause of bleeding was assessed endoscopically using standard criteria for active and recent bleeding, and relevant endoscopic treatment was given depending on the cause. Gastric varices were defined according to the Sarin classification [2]. Gastric biopsies were done in patients with peptic ulcers and histological assessment was done by a consultant histopathologist. Normal examination was defined by the absence of any endoscopic abnormality.
The majority of patients (858 - 69.19\%) were males (mean age of 61.2 years). Portal hypertension was the cause of bleeding in 714 (57.58\%) patients and peptic ulcer disease related causes accounted for 466 (37.58\%) bleeding episodes (Table). Endoscopy was performed within 24 hours of the bleeding episode in 702 patients (56.6\%) and the cause of bleeding was detected in the majority (98.5\%). Out of 714 patients with portal hypertension 686 had cirrhosis of the liver; $58 \%$ of them were alcoholic and 37\% were cryptogenic. There were 3 patients with haemo-chromatosis, 9 with autoimmune cirrhosis, 7 with Wilson disease, 6 with hepatitis $C$ and 4 with hepatitis B. Prevalence of diabetes mellitus was considerably higher in the cryptogenic cirrhosis group (48.6\%, M:F =1:1.8) compared to the alcoholic cirrhosis group where only $23.1 \%$ were diabetics (all were males). Twenty four (3.6\%) out of 654 patients had an extrahepatic cause for portal hypertension.

Table

\begin{tabular}{|c|c|c|c|c|c|}
\hline \multicolumn{2}{|l|}{ Endoscopic findings } & \multicolumn{2}{|l|}{$n$} & \multicolumn{2}{|l|}{$\%$} \\
\hline \multirow[t]{6}{*}{ Portal hypertension related } & Oesophageal varices & 572 & 714 & 46.5 & 57.6 \\
\hline & GOV $-1 *$ & 9 & & 0.8 & \\
\hline & GOV -2 & 60 & & 4.8 & \\
\hline & IGV-1 & 6 & & 0.5 & \\
\hline & IGV-2 & 1 & & 0.1 & \\
\hline & Portal gastropathy & 24 & & 1.9 & \\
\hline \multirow[t]{4}{*}{ Peptic ulcer disease related } & Duodenal ulcer & 62 & 466 & 5 & 37.6 \\
\hline & Gastric ulcer & 286 & & 23.06 & \\
\hline & Erosive gastritis & 68 & & 5.5 & \\
\hline & Erosive oesophagitis & 50 & & 4 & \\
\hline \multicolumn{2}{|l|}{ Mallory Weiss syndrome } & 28 & & 2.3 & \\
\hline \multicolumn{2}{|l|}{ Other $^{\phi}$} & 14 & & 1.1 & \\
\hline \multicolumn{2}{|c|}{ No localization (normal endoscopy) } & 18 & & 1.5 & \\
\hline
\end{tabular}

*Sarin classification. ${ }^{\oplus}$ Gastric tumour - 3, dieulafoy lesion - 4, angiodysplasia - 2, oesophageal ulcer - 3, duodenal A-V malformation - 2. GOV - gastro-oesophageal varices, IGV - isolated gastric varices. 
This study shows that oesophageal varices (46.5\%) were the commonest source of upper gastrointestinal haemorrhage, and that alcoholic cirrhosis was the leading cause of portal hypertension. Our findings are comparable to a previous report from Sri Lanka on this acute medical emergency [1].

Medication was the main cause $(82.9 \%)$ of peptic ulcer related bleeding and only $21.1 \%$ of peptic ulcers were positive histologically for Helicobacter pylori infection. More than 50\% of patients with peptic ulcer bleeding had been taking aspirin with or without clopidogrel. The number of NSAIDs users was small.

\section{References}

1. De Silva HJ, Fernando DPA, Wickramasinghe SYDC, De Silva PT, Dharmadasa K. A study of acute upper gastrointestinal haemorrhage. Journal of the Ceylon College of Physicians 1985; 18: 29-42.

2. Sarin SK, Lahoti D, Saxena SP, Murthi NS, Makwana U. Prevalence, classification and natural history of gastric varices: a long term follow up study in 568 portal hypertensive patients. Hepatology 2005; 16: 1343-4.

\section{N M M Nawarathne ${ }^{1}$, U L Thoufeek ${ }^{1}$, V Abeysuriya ${ }^{2}$, A lleperuma ${ }^{3}$}

${ }^{1}$ Gastoenterology Unit, ${ }^{2}$ Surgical Unit, ${ }^{3}$ Department of Pathology, National Hospital of Sri Lanka, Colombo.

Correspondence: NMMN, e-mail <navarathne@gmail.com>. Received 2 February and revised version accepted 15 June 2010. Competing interests: none declared. 